\title{
An Assemblage of Thai Water Engineering: The Royal Irrigation Department's Museum for Heavy Engineering as a Parliament of Things
}

\author{
JAKKRIT SANGKHAMANEE ${ }^{1}$ \\ CHULALONGKORN UNIVERSITY
}

\begin{abstract}
In Thailand, where water and land intertwine to shape the livelihood and identity of people, engineering bureaucracy and mechanical technology have both played significant roles in producing national ideology. At the same time, bureaucracy and technologies are historical products. In this contribution, I explore Thailand's Royal Irrigation Department (RID) Museum for Heavy Engineering and argues that the museum-instantiating a parliament of things (Latour) engineered into exhibition-participated in the shaping of the Thai water engineering community and the shaping of Thai statecraft. Operating through selective portrayals and juxtapositions of engineers, technologies, bureaucracies, and natural events, the parliament of things composed by the exhibits encompasses not only the intimate entanglements between the bodies of engineers and machines, and between machines and bureaucracy, but also mythical and cosmological elements like divine stones and naga vehicles. In this way, the museum parliament testifies to a blurring of nature, society and divinity occurring at the very heart of the Thai engineered state. It articulates Thai water engineering as a nonmodern assemblage beholden neither to the dichotomy of nature and culture, nor to any clear distinctions between science, politics and cosmology. Paradoxically, this nonmodern assemblage has been central in propelling forward the seemingly high-modern practice of Thai water engineering.
\end{abstract}

\section{Keywords}

Royal Irrigation Department; Thailand; parliament of things; statecraft; water engineering

\section{Introduction}

In Thailand, as elsewhere, engineers and their technologies have served the national goal of modern development. Because of Thailand's amphibious geography, water engineers have played a central role in this project. For more than a century, they have invented and tinkered with machines that would help them create and maintain canals for irrigation and transport, build dams, and prevent flooding.

' Jakkrit Sangkhamanee, Email: jakkrit.mail@gmail.com

Copyright (C) 2017 (Jakkrit Sangkhamanee). Licensed under the Creative Commons Attribution Non-commercial No Derivatives (by-nc-nd). Available at estsjournal.org. 
Yet, while Thai engineers have busied themselves making machines to alter landscapes, these machines also made the engineers. Moreover, they shaped the bureaucracy within which they operated, giving it a distinct, nonmodern, form. Engineers, machines, and bureaucracy were shaped by multiple other elements, including royal support, delta landscapes, and even myth and cosmology. In this paper, I analyze the resulting amphibious assemblage that makes up Thai water engineering.

Located on the outskirts of Bangkok, the Royal Irrigation Department (RID) Museum for Heavy Engineering is an ideal location for understanding the emergence and historical transformation of this assemblage. In the museum, the works and lives of engineers are displayed and narrated and their machines are exhibited. More than classifying and displaying engineers and machines as distinct kinds, however, the exhibits also brings to life their intimate entanglements.

At a first glance, the museum seems to illustrate the separation of human and nonhuman worlds, which Latour (1993) sees as characteristic of "the moderns." Upon further inspection, however, the museum appears more like a hybrid "parliament of things." In some ways, the hybridity depicted in the museum even exceeds the binary of nature and culture from which Latourian hybrids are made. Tracing the complex interrelation of engineers, landscapes, bureaucracy, statecraft, and myth depicted in the exhibits, my analysis elicits the museum as a particular, and peculiar, parliament of things. Doing so, it articulates the nonmodern characteristics of the Thai water engineering assemblage.

\section{The Museum as a Parliament of Things}

In his analysis of the relation between modern techno-science and politics, Patrick Carroll (2006) outlines an analytical approach in which discourse, practice, and materiality are "triangulated." Discourses include visions and ambitions, representations, and ideologies in support of highmodernist interventions in nature. They are interlinked with practices, understood as social and organizational activities that make discourses tangible. In turn, the proliferation of both discourse and practice depends on varied forms of materiality, like machines and infrastructures. According to Carroll (2006: 24), the triangulation of these domains made it possible for modern engineering cultures to straddle science and government. As he summarizes, the modern state is, "by definition, an engineering state" (23).

Carroll's observation is important because technology museums, like the RID museum, are regularly analyzed as places where the conjunction of technological and state power is made explicit and celebrated. In the words of Chandra Mukerji (2003: 655), they can be seen as displays of "material intelligence and stewardship over nature" that testify to the right of states to rule by demonstrating their ability to rule well. The RID museum, too, depicts the history of Thai water engineering and technology in terms of a continuously improving capacity to control amphibious landscapes. In this sense, the museum does indeed symbolize the techno-political power of the RID, legitimizing its expertise and authority. However, more is going on as well.

Aside from displaying the technological advancement of Thai Water engineering, the 
RID museum also depicts the changing relations between engineering and formal bureaucracy. According to Max Weber's (1978) classical discussion, bureaucracy is characterized by spiritual disenchantment and dispassionate rationalization. On this basis, Colin Hoag (2011: 81-84) has described it as an "objectivity machine." Yet, while there is an explicit machinic dimension to the RID bureaucracy, which was indeed repeatedly reorganized through the introduction of new machines, this system does not otherwise conform to Weber's image of increased rationalization and objectivity. Rather, the dynamic and contingent process that shaped the RID bureaucracy never ceased to mix up the conventional Weberian elements with things like monarchic and engineering charisma, not to mention with cosmological themes relating to divinity and water spirits. It can even be argued that what Weber called the "power position of bureaucracy"according to which the technical expertise and administrative control of bureaucrats can bestow upon them a power that exceeds that of sovereign-is reversed. In the case of the RID, that is, the power held by the bureaucracy is due not only to attachments with the monarchy; it is also underpinned by mythical agencies, like those of naga serpents.

In the following, I argue that the RID museum articulates a particular form of hybridity characteristic of Thai water engineering. To grasp the nonmodern features of this assemblage, I activate Bruno Latour's notion of the "parliament of things." As is well known, the parliament of things was Latour's (1993: 93) alternative to the "modern constitution," composed of transcendent Nature and immanent Society, and excluding any divine power. Latour (1993: 139) emphasizes that the modern constitution is premised on simultaneously holding together nature and society, while also keeping them "strictly separate." By pinpointing the de facto practical mediation of nature and society, which occurs in spite of their principled "strict separation," Latour captured the paradox at the core of Western modernity. Because the modern constitution allowed "the expanded proliferation of the hybrids whose existence, whose very possibility, it denies," the moderns were able to "mobilize Nature, objectify the social, and feel the spiritual presence of the God, even while firmly maintaining that Nature escapes us, that Society is our own work, and that God no longer intervenes" (1993: 34).

Because Latour's parliament of things refuses to acknowledge the separation of people and things, nature and society, and emphasizes instead their constitutive hybridity, it offers an alternative to the modern constitution. Constitutive hybridity thus lies at the center of his famous actor-network analyses: subjects and objects, science, technology, bureaucracy, and state power are all understood as hybrids, quasi-objects and quasi-subjects, whose very existence and characteristics are effects of heterogeneous relations.

In some ways, the difference between this understanding and the triangulation proposed by Patrick Carroll appears slim. Indeed, in a formulation that strikingly resembles Latourian formulations, Carroll (2006: 26) writes that: "while it makes sense in one context to speak about a relationship between science and the state, in another it is more appropriate to speak of a complicated entanglement of things material and immaterial, human and nonhuman, in an elaborate socio-technical network." Below, I trace such complicated entanglement through the museum's depictions of engineers, machines, bureaucracy, and cosmology.

Yet, the very intimacy of these entanglements also problematizes the assumption that 
there are distinct domains to be triangulated. While the notion of triangulation remains committed to the modern constitution-simultaneously seeing objects and subjects as related but also keeping them strictly separate-analyzing the museum as a parliament of things thus facilitates a view of the engineered state as a scene of ontological assembly and transformation.

To analyze the museum as a parliament of things entails paying close attention to the way it depicts processes of ontological assembly. But for all that, the primary focus of this paper is not on the museum exhibits. Rather, by walking the reader through the exhibits, I intend to develop an analysis of the relations and transformations characteristic of the assemblage of Thai water engineering. Since the museum itself is also part of this assemblage, its exhibits can be seen as political materials (Jensen 2015) that perform a particular labor of ontological opening and stabilization.

While the museum in some ways celebrates the brilliant engineers expected to use technology efficiently for state development, in other ways it challenges and complicates the clear image of high-modernism. For one thing, as we will see, the exhibits move freely between objects and subjects, and between nature and society. While depicting the building of dams as an achievement of modern heroic engineering and efficient bureaucracy, the exhibit also brings into the story divine kingship, myth, and cosmology.

I first examine the museum's depiction of the career of the legendary engineer Chulanope. In one sense, this narration conforms to the conventional idea of heroic engineering. At the same time, this famous man is exhibited as a hybrid actor composed of his relations with many machines, forms of bureaucracy, royal power, and flooded delta landscapes. Second, I analyze the historical co-evolution, or "mangle" (Pickering 1995) of machines and bureaucratic organization at the RID. Finally, I examine the "myths" and "cosmologies" located at the center of Thai dam development and machine use. That these are not simply "symbolic additions" to the "real practices" of Thai water engineering, indicates that this is indeed a nonmodern assemblage that exceed the modern constitution.

\section{A Museum of Amphibious Things}

Inaugurated in 2007, the Royal Irrigation Department Museum for Heavy Engineering is located near a curve of the Chao Phraya River on the outskirts of Bangkok. Covering 10,574 squaremeters of indoor and outdoor exhibitions, the main building is a modern loft-house shaped like a naga-a mythical, amphibious serpent related to the Buddhist idea of rain, fertility, and moral multiplicity-rising above water. Carrying a logo that looks like a wheel gear moving above a current of flowing water, the banner in front of the building reads: "The RID Museum for Heavy Engineering in Commemoration of Chulanope Snidvongs Na Ayudhya, Privy Councilor." The landscape surrounding the museum features a human-made pond in the shape of a wheel gear, symbolizing the engineering capacity to manipulate natural resources for the nation (RID 2007a). The juxtaposition of cosmology (in the form of the naga), bureaucracy (in the form of the banner), and machines (in the form of gears) is immediately suggestive of the ontological multiplicity of this place. 
The museum interior houses a great range of machines that have been used for state irrigation and water management projects. Some were imported, while others were made by RID's own technical staff and engineers. Moving across landscapes and waterscapes, the museum exhibits show them connecting and transforming the worlds of engineering and bureaucracy as well as Thai delta landscapes.

Walking into the hall, the visitor is guided through three exhibitions. In the following sections, I analyze how these exhibitions compose a nonmodern parliament of things. Made up of pictures and narratives, the first exhibit, titled "The Biography of Chulanope Snidvongs Na Ayudhya," portrays Chulanope as a brilliant engineer who served the nation and the King by inventing numerous machines, modernizing the RID factory, building dams, and protecting the land against natural catastrophe. The second hall is called "The evolution of Machine Use and Design for RID works." Here, the bureaucratic and technological evolution of RID Machinery is articulated with simultaneous reference to machines, reigns of monarchy, various great men, and the restructuring of bureaucracy. Finally, "With Our Brains and Machines" depicts machines as part of national development, in particular highlighting RID's involvement in the building of Thailand's famous dams. All of this sounds perfectly sensible for an engineering museum built to promote state-supported, technological modernization. As we look more closely at the exhibits, however, the image of Thai water engineering quickly becomes more complicated, and quite a bit stranger.

\section{Chulanope: More Than a Legend}

Entering the exhibition in Hall One, one encounters an imposing portrait of the engineer Chulanope. ${ }^{2}$ After an illustrious career at the RID, Chulanope came to epitomize the figure of the heroic engineer in Thailand. Equaled only by Xujati Khambhu, the Father of Thai Watermen (RID 1966, 1969; Sangkhamanee 2010), his legendary trajectory is narrated in the exhibit.

At around 8.30 a.m. on November 4, 1989, the typhoon Gay, conceived by a monsoon trough over the lower Gulf of Thailand, unexpectedly moved into the narrow peninsula. Gay was the first typhoon since 1891 to make landfall in Thailand, and the most rapid and disastrous typhoon to affect the Malay peninsular in 35 years. With wind speeds up to $185 \mathrm{~km} / \mathrm{h}$, the storm initially hit three districts in southern Thailand. Ashore, it struck five more districts and created a series of gigantic mudslides, containing thousands of logs that had been illegally cut and left in the mountains. These mudslides cut off most public transportation and caused damage to around 38,000 households and 154,000 people. Local infrastructures and buildings including irrigation dams, schools, temples, and mosques, as well as the agricultural land of more than 183,000 hectares were devastated. The monster of wind and water caused 458 recorded fatalities.

Soon after the catastrophe, a team of high-ranking bureaucrats led by Chulanope, who by

2 The descriptions of Chulanope in this and the following sections are based on three main sources: the content of the exhibition at the RID Museum of Heavy Engineering in 2007, the RID's book published and distributed for the opening ceremony of the Museum (RID 2007a), and the cremation volume of Chulanope Snidvongs Na Ayudhya (2007). 
then held a senior position as Permanent Secretary of the Department of Agriculture, flew by helicopter to evaluate the damage. Coupled with the rubber and coconut plantations felled by the typhoon, one of the main risks was that the huge piles of logs that had tumbled down might fuel a fire. After conducting a quick reconnaissance, Chulanope took a leading role in establishing measures for fire prevention. Returning to Bangkok, he immediately printed manuals with maps and a thorough guideline of operations (RID 2007a).

With the help of more than 200 tractors and other machines dispatched from RID's countrywide units, the vast piles of illegal logs were swiftly cleared. Then, a more than $1,000 \mathrm{~km}-$ long fire barricade was constructed. After completing this massive task, Chulanope ordered the idle tractors and trucks to dig more than 1,800 ponds to provide immediate water sources within the resettlement areas where affected populations had been relocated. Chulanope's planning and management of the post-disaster recovery, and his efficient mobilization of machines and manpower from all over the country, was praised in bureaucratic circles. Locally, too, he became legendary. Anyone who visits the area today will find a monumental pavilion reminding visitors of his bureaucratic and engineering achievements. In 2007, top-ranked administrators and engineers decided to name the Museum for Heavy Engineering after Chulanope, in commemoration of his lifelong commitment to the improvement of the Department's machinery (RID 2007a). Though Chulanope passed away in 2006, his name and legend thus survive, carried on by his machines and the museum.

It is not unusual for either organizations or museums to narrate success and progress as a consequence of the heroic agency of engineers. Yet Chulanope's position in the museum is both more complicated and more ontologically interesting. Specifically, as I show in the next section, the exhibit offers a picture of Chulanope as something more and different than a legend. He is shown as a hybrid actor, composed of such diverse threads as heroic agency, practical education, bureaucratic finesse, royal connections and, not least, a life of intimate relations with many kinds of machines.

\section{A Man of Walking Draglines}

Born into an extended royal family, in 1951 Chulanope received his bachelor's degree in Mechanical Engineering from Chulalongkorn University, the country's most prestigious academic institution. He then took up a position as junior engineer in the excavator section of the RID. However, he quickly realized that his formal school knowledge was of limited use for his new work amidst the machines (Snidvongs Na Ayudhya 2007).

At the time, the section owned around 15 excavators. Most were very old; some spent

\footnotetext{
${ }^{3}$ An excavator, also known as a digger, is a moveable machine used mainly for heavy construction and landscape development. The machine consists primarily of a movable and rotatable platform, a motor body with a controlling cab on the top where the driver is seated, and a bucket. The excavators first used by the RID were of a dragline type, in which the bucket is sling-tied with the boom and the body of the machine. The operation requires power generated from different kinds of sources depending on its type and its technological advancement, ranging from steam to hydraulic diesel engines.
} 
most of their time in repair. To get a sense of these machines, we can consider the displays of Excavators No. 1 and No. 2. Driven by steam, each weighed more than 200 tons and required rails for transport. Moving these machines even five meters required 30 to 40 people for operation, feeding of fuel-wood, and laying down moveable rail tracks. Other types included diesel-run crawler excavators, also older models. Soon after Chulanope began working at the RID, 200 new walking-dragline excavators arrived. As they were not ready-made, their assembly required extensive labor, skills, and time. Chulanope honed his engineering skills on these machines.

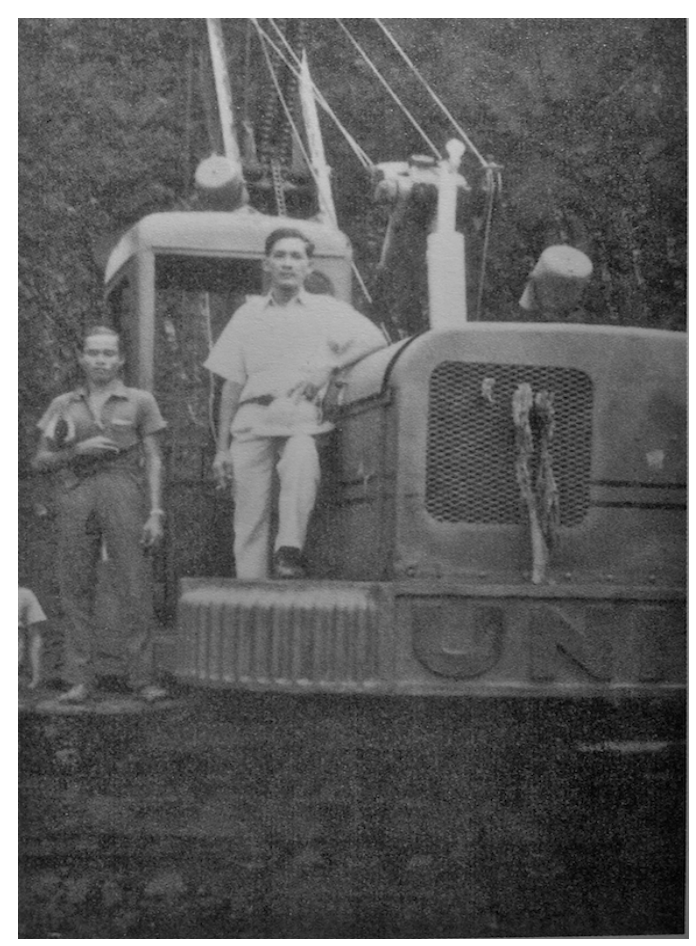

Figure 1: Chulanope with Walking-Dragline

Around this time, Thailand was about to embark on the construction of the Chao Phraya dam, a structure of unprecedented size. The dam had originally been proposed by the Dutch engineer Homan van der Heide back in 1903 when he had conducted a survey of the delta basin (Brummelhuis 2007). Almost half a century later, the project would be brought to fruition with the support of funds from the World Bank (Biggs 2006). Ever since, one of the most important reference points for the success of Thai water engineering has been its large dams. During early 1950s, the RID succeeded in getting financial and technical support for the Chao Phraya dam, mainly from the US government and the World Bank. Despite his junior position, Chulanope was 
put in charge of multiple tasks. They ranged from clerk jobs, inventory, and technical works to enlisting and buying excavators from abroad. He also became directly involved in assembling the imported machines. In assembling the machine, the excavator team started with the smaller-size excavators, then used them as cranes to lift the bigger parts needed for the larger machines. Once assembled, the machines had to be transported to the sites where they'd be put to work. Within the topography of the river basin, this turned out to be very difficult. Requiring multiple methods of transportation (the dragline excavators depended on trailers, ferries, rails, slings, cranes, trucks) as well as bridges and roads.

Illustrating these practical difficulties, the museum's commemorative book (RID 2007a) narrates how the excavators once fell into a river. To rescue the sunken machines, divers donned snorkeling equipment and used heavy metal balls to descend. They then sketched the position of the machines in order to analyze possibilities for retrieval. On this basis, the excavators were dismantled underwater and brought back to the surface piece by piece, using slings and forklift trucks. The whole operation lasted over a week.

Chulanope developed both his organizational and engineering capacities while working under these tumultuous conditions. Moreover, his own subjectivity and agency were assembled in the same process. This is vividly suggested by the name "a man of walking draglines" (Snidvongs Na Ayudhya 2007) given to Chulanope by his peers in recognition of his deep knowledge of, and intimate connections with, these machines (RID 2007a). In turn, these unusually close connections with machines facilitated his stellar career within the RID. Chulanope's rise to power, and the gradual ascription to him of legendary qualities, is in no small measure an outcome of his life-long dance of agency with the machines.

\section{Inventing Machines, Extending Monarchy}

After working for two years in the Excavator Section, Chulanope was sent for a year of training to the United States. There he visited the Caterpillar, Bucyrus-Erie and Westinghouse companies in Illinois, as well as Cooper Bessemer in Pennsylvania. At the suggestion of the Head of the RID, he subsequently continued his studies abroad, concentrating on heat power engineering at the University of Michigan.

Upon his return, he began working in the Mechanic Manufacturing Section. From this position, Chulanope added to his status by inventing new machines. His inventive zeal is made clear by the fact that he successfully devised and modified nearly a thousand machines over the span of his career (RID 2007a). They ranged from small devices, like a hydraulic ram, to gigantic components of mega projects, such as the sluice gates of a dam.

To provide a flavor of this inventive practice, we can consider his modification of the hydraulic ram. This was a self-contained hydropower water pump, operated by using water from local weirs or reservoirs, which was fed into a tube using a gate valve to control the supply head. The flow rate and hydraulic pressure closed a waste valve, and the increasing pressure in the valve box pushed a feeding valve that allowed for more than 80 percent of the inflow of water to pass into an air vessel. It was then pushed through a check valve into a reserve tank at a higher 
position. Gradually, the water pressure within the tube would decline, causing the feeding valve to close and the drainage valve to open. In this way, a cycle of continuous hydro-mechanic action was completed. This design has since been used in many rural and mountainous areas where electricity is inaccessible.

Similar to the invention of the Diesel engine examined by Latour (1987), in which networks consisting of scientists, engineers, manufacturers, companies, and other machines and equipment were associated and translated into a functional engine, the hydraulic ram was not the exclusive invention of the Department, or of Chulanope himself. For one thing, it drew on previous innovations by Whitehurst and Montgolfier, who had also been involved in the invention of hot-air balloons (Ferguson and Patterson 2013). Yet, what was distinct about the hydraulic ram was its modification, undertaken on King Bhumibol Adulyadej's advice, in order to make it simultaneously fit local contexts of use and the ongoing bureaucratic expansion of irrigation provision in support of national agricultural development.

Chulanope served in several water-related projects initiated by the King, who was an aficionado and staunch supporter of the water sciences and engineering. Indeed, a large part of the exhibition in Hall One is dedicated to the portrayal of Chulanope's royal services. Even after retiring from the Ministry of Agriculture, Chulanope continued to work for many of the King's water development projects. His strong ties with these prestigious projects made him widely recognized beyond the engineering community (Snidvongs Na Ayudhya 2007). In 1991, Chulanope was appointed the King's privy councilor.

There is little doubt that Chulanope's career as an elite technocrat was enabled by his own royal pedigree. Clearly, however, more was involved than his existing power and privilege. For one thing, the King was very invested in water science and engineering, though obviously unable to involve himself in the nitty-gritty of project implementation. For another, Chulanope was recognized far and wide for his deep working knowledge of excavators, his useful inventions, and his organizational abilities. Due to the importance of irrigation, water engineering is located at the core of Thai nation building. Thus, Chulanope's career unfolded at the very heart of the engineered state. Here we find no separate domains of science and technology and state. Instead, what the museum depicts is a process of mutual constitution in which the invention and deployment of machines functioned as an extension of monarchy, while royal privilege and support facilitated the extension of water engineering (McCargo 2005, see also Blake 2015). While the King thus did water engineering through Chulanope, Chulanope did politics through water engineering.

\section{Mangling Machines and Bureaucracy}

Hall Two presents the evolution of machines used in RID projects. A number of eminent machines and instruments, real and mock-up, are exhibited sequentially. They are accompanied by brief technical information and descriptions of the circumstances of their invention and period of use. In Hall Three, one continues to learn about the evolution of RID technologies and their deployment in large dam construction. At the same time, one learns about the simultaneously 
evolving bureaucracy. For example, a detailed timeline depicts the parallel development of irrigation technology and RID bureaucracy, showing the names and pictures of the leading bureaucrats and engineers of different time periods. Thus, the exhibits depict machines as an integral part of hydro-bureaucracy. They narrate a "mangled" history in which bureaucratic organization and classification transformed in tandem with the arrival of new machines.

In 1902, the nation's first water administration, the Canal Department, was established. The department relied on a great number of machines, including dredging boats, navigation gates, and sluice gate controllers. At the time, the Machinery Section of the department consisted of two main units-one for technicians and one for machinery (RID 1986). This organization categorized things according to the demands of modern bureaucracy, while also exceeding its Weberian form. While the Technician Unit focused on recruiting, training, organizing, and building the "social" subjectivity of the Thai community of "watermen" (Sangkhamanee 2010), the Machinery Unit dealt with the "objective" side, including physical materials and mechanic operations. The division, therefore, appears to directly reflect the modernist separation described by Latour. Yet, the accompanying flowchart mangles these categories by continuously reconfiguring these relations. In the following, I translate this flowchart into narrative.

In 1905, we read, two steam-dredging boats were acquired. These boats were used mainly to maintain existing canals and to dig new routes for riverine commuters within the Bangkok area. Some years later, an extensive network of irrigation canals was completed in the Rangsit area north of Bangkok, and the focus of national development turned towards agriculture (Brummelhuis 2007). Reflecting this reorientation, the canal department became the irrigation department in 1914.

A few years later, in 1919, the existing reservoir and extensive irrigation canals faced a severe drought. At this point, the department acquired water pumps to support the dredgers. Decades later, when the Chao Phraya dam was under construction in the central plain, four new dredging boats were acquired for operation outside Bangkok. After the completion of the dam, they expanded irrigation routes in the lower part of the basin (RID 2007b).

In the 1950s, a large factory was built as part of the new RID headquarter on the Chao Phraya River, in preparation for the building of the Chao Phraya dam. More than a hundred imported machines-from gear-cutting and metal-shaping machines to lathes and steel-melting furnaces-were used in this factory, which became Thailand's largest site of machine manufacture.

The RID thus became the home of many new machines. At the same time, the exhibit narrates a temporal lag between these new technologies and Thai bureaucrats' and engineers' old ways of working. After just a few years of operation, the factory was run-down. Meanwhile, the workers had become irritable and ineffective due to low or missing salaries.

In the museum commemoration book, one can read about Chulanope's pivotal role in cleaning up this technical and organizational mess. First, he guided the repair of machines and instruments. He also ordered the machines to be repainted in a vibrant green color to enliven the atmosphere. Then, he set to work solving the financial problems of the factory, aiming to improve employee motivation by ensuring they would be paid. Due to his success productivity soared. 
Museum statistics show that prior to Chulanope's arrival in 1959 one thousand workers produced around 400 tons of steelwork annually. Four or five years later, fewer than 400 workers produced more than 1,000 tons per year.

In 1959, a Hydropower Unit was established to serve the construction of the first hydropower plant and the biggest dam in Thailand. Built on the Ping River, one of the Chao Phraya tributaries, and named after the King, the Bhumibol dam would be a multi-purpose concrete arch dam. In connection with this massive project, the RID bureaucracy once again expanded its operations. Its main task was to produce winch machines, sluice gates and navigation locks, as well as mechanic parts to substitute for imports. Yet later, during the mid1970s, the RID missions expanded into land reclamation and agricultural extension, partly due to the influence of US Bureau of Reclamation, and financial provision from the Food and Agricultural Organization (Sangkhamanee 2010). The increasingly extensive irrigation canals required excavators, cement mixers, water pumps, and numerous irrigation outlets. To make do with its limited budget, the RID Manufacturing Section thus also began to devise its own machines.

The timeline depicts a steadily increasing intimacy of machines and bureaucracy ever since the construction of the first mega-dams. In 1984, the RID established five new administrative units, each of which focused on particular machines: Units of Soil Machines, Transportation Machines, Machinery Factory, Mechanical Engineering, and Machines for Communication. Two decades later, these administrative units had morphed into Mechanical Engineering, Transportation Machines, Machinery Factory, Excavating Machines, Tractors, and Dredging Boats, and an additional seven Mechanical Operation Centers located in regional offices.

Testifying to the hybridity of Thai water engineering, hall two and three thus exhibit machines and bureaucratic classifications as mangled and co-evolving. Over and again, the new machines acquired to enable RID to operate in the delta led to reconfigurations of its bureaucratic structure, thus producing a machinic bureaucracy more reminiscent of Latour's parliament of things than Weber's iron cage.

However, in spite of their omnipresence, machines, engineers, and bureaucratic departments do not make up the entirety of Thai water engineering. In the following sections, I pay close attention to the museum exhibits in order to identify a set of more distinctly nonmodern elements that also played vitally important roles of the Thai water engineering assemblage.

\section{Dams and Divinity}

In Concrete Revolution, Christopher Sneddon (2015) analyzes dams as central hubs-dam assemblages-that draw together techno-scientific expertise and geopolitical dynamics in historically specific, and concrete, trajectories. In the Thai context, too, dam assemblage is an apt characterization of how dams function at once materially--embodying architecture and technology on a grand scale, and operating as a kind of water colossus-and symbolically, 
offering socio-political representations of the national capacity to control nature. For Sneddon, therefore, dams are intersecting points of nature and culture-zones where science and politics are mediated and stabilized. In Thailand, however, some aspects of infrastructure development exceed these binaries.

When the construction of the Bhumibol dam was about to commence, the King and Queen presided over the opening ceremony. In Thailand, the ceremonial placing of a founding stone prior to the construction of any significant building or infrastructure is common. The museum's photo exhibition shows the RID and its techno-bureaucrats in many similar ritual situations, like the construction of Chao Phraya dam, the opening of the RID machinery factory, and Chulanope's post-typhoon monumental pavilion. Thus, dams and other hydroinfrastructures exhibit the co-existence of multiple, seemingly incommensurable elements-ecology, science and engineering, divine authorities, human agency, technological and symbolic materials as well as monarchic power--within the same ontological assemblage.

On the day of the royal inauguration of the dam, a 60x40x60 centimeter stainless steel box was prepared. Inside the box, engineering blueprints of the dam were rolled into a waterproof tube along with nine bricks made of silver, gold and copper. The King then placed the founding stone, gilded by gold leaves and engraved with a Brahmanic astrology diagram and descriptions of ceremonial auspiciousness, next to these items. The sealed box was placed in a hole under the dam's foundation, located exactly 150 meters below the seat of the King (RID 2007a). This ceremony juxtaposed modern things (like engineering blueprints) with royal things (like golden bricks) and cosmological things (like astrological signs of auspiciousness). During the ceremony, multiple, seemingly incommensurable authorities-technology, cosmic divinity and monarchywere each recognized, mutually aligned, and stabilized as part of performing the legitimate authority of Thai water engineering. The insertion of the literally black box into the center of the dam structure can be understood as a sanctification of infrastructure that is simultaneously material and immaterial.

Composed of ontologically variable elements, including cosmological ones, hydropower infrastructures in Thailand go beyond techno-science and politics in its Western guises. Indeed, the ceremony articulated the interior of the dam as a place where the inside of technology melds with the inside of Thai mythology. By encompassing those cosmological or "mythic" dimensions, which Latour locates on the outside of the nature-society binary, they exceed the modern constitution.

Divine foundation stones may indeed seem like an anomaly, detracting from the more everyday processes of technological adaptation, which make up most of the RID work. Yet, many mundane examples testify to similar kinds of excess. Not only displayed in grandiose ceremonies, common machines like naga boats and trucks also go beyond the socio-technical binary. The naga is a serpent-like mythical creature based on canonical Buddhist legends. This amphibious creature is said by Thai and Lao people to reside in the Mekong River and other local bodies of water. If lucky, one may also find its slithering trace on land.

According to Buddhist cosmology, the naga provides water to people by taking the form of falling rain. As described by Jumsai (1988), the naga figures prominently in architecture and is 
central to many religious ceremonies. It is also commonly found embedded in cultural artifacts in Thailand (and throughout mainland Southeast Asia)—including at the RID.

In the early 1920s, extensive drought, coupled with the reorientation of national development towards agriculture, gave birth to the first batch of naga boats. Invented in 1922, these boats were modified iron boats with an installed Worthington centrifugal water pump and a Diesel engine. Their technical purpose was to provide irrigation, supply water, and alleviate flooding.

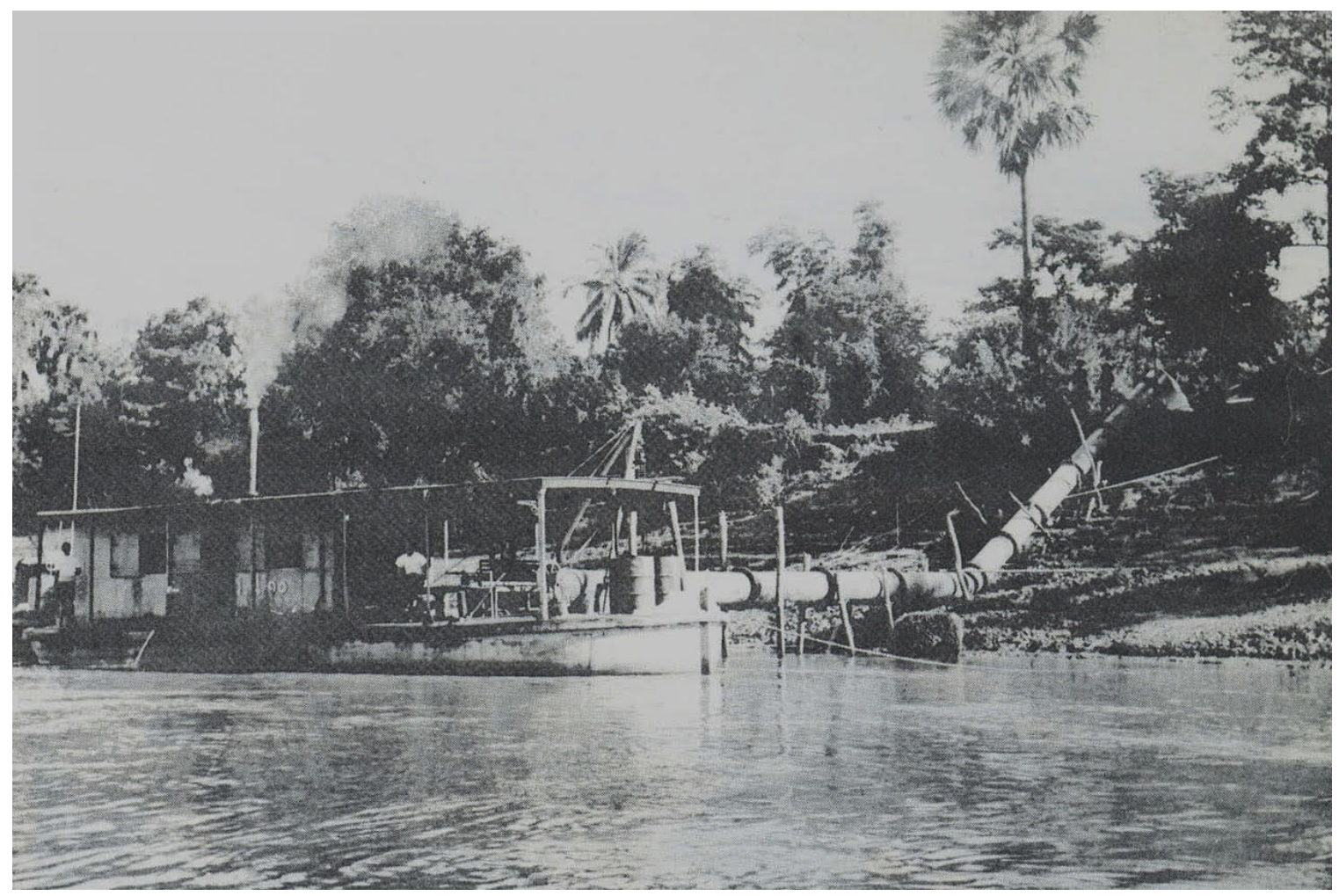

Figure 2: The Naga Boat

The sibling of the naga boat, the naga truck, was a modified Ford installed with a Torishima centrifugal water pump and a Diesel engine. In the museum, pictures and models of naga boats and trucks are displayed as success stories of how local engineers modified foreign machines to serve local conditions. As the naga boats and trucks traveled to remote areas, they carried with them both the technical actions of engineers and the divine powers of the state. Moreover, they brought along mythical powers such as the capacity to provide rains and fertility. The exhibit suggests that the success of these machines in rural conditions can be attributed to this combination of the bureaucratic, the technical, and the mythical. As nonmodern, political materials, the naga boats and trucks thus created a conduit between engineering and divinity. 
While the parliament of things exhibited at the RID museum on the one hand evokes a pervasive image of techno-bureaucratic capacity and the successes of Thai modernization, I have indicated that it does much more than that. It ties together the material and the immaterial. It interweaves technology, politics and myth. Machines are shown as mangled with numerous other entities, including engineers, changing forms of bureaucracy, natural catastrophes, royal ambition, astrological predictions, and spirit-laden naga boats. What emerges is an image of Thai water engineering as a profoundly heterogeneous and nonmodern assemblage, which acknowledges the co-existence of people, machines, and spirits on the same ontological plane.

\section{Conclusion}

In this article, I have examined the RID Museum of Heavy Engineering as parliament of things, which exhibits the historically changing assemblage of Thai water engineering. Casper Bruun Jensen (2015) has proposed that STS scholars view infrastructures as ontological assemblages composed and re-composed by a wide variety of unpredictable elements. In his description (Jensen 2015:17), infrastructures appear as "cauldrons in which multiple forms of political materials intermingle and through which practical ontologies emerge." Though the RID museum itself is not an infrastructure, Jensen's description is equally fitting for its exhibitions. It displays a parliament of things within which multiple materials have amalgamated over time, thereby producing the assemblage, or "practical ontology," of Thai water engineering.

Latour's "parliament of things" and Jensen's "political materials" both gesture at the importance of politics. Indeed, if we consider the constant visibility of royal power at the museum, its emphasis of Thai engineering capacity to successfully deal with the unruly delta landscapes, and its narration of Chulanope's legendary achievements, it might seem that the museum is about little else. Thus, it can be argued (Carroll 2006: 13), that the museum performs "an ideology of legend," that celebrates Thai water engineering "in terms of heroic and stoic individuals struggling against irrationality, ignorance and obfuscation" (Carroll 2006: 13). According to this view, the point of the museum would be to live up to "the demands and expectation of statecraft" and secure on behalf of water engineering "the blessing of government" (13).

Yet, though the people and machines on display at the museum are certainly associated with the power of state, the exhibits also complicate the heroic narrative (cf. Latour 1996). Operating through selective portrayals and juxtapositions of engineers, technologies, bureaucracies, and natural events, the parliament of things composed by the exhibits encompasses not only the intimate entanglements between the bodies of engineers and machines, and between machines and bureaucracy, but also mythical and cosmological elements like divine stones and naga vehicles. In this way, the museum parliament testifies to a blurring of nature, society and divinity occurring at the very heart of the Thai engineered state. It articulates Thai water engineering as a nonmodern assemblage beholden neither to the dichotomy of nature and culture (Descola 2013), nor to any clear distinctions between science, politics and cosmology. Paradoxically, this nonmodern assemblage has been central in propelling forward the seemingly 
high-modern practice of Thai water engineering.

Latour defined the task of his parliament of things concept as enabling an ontological politics (cosmopolitics) by patching together the artificially separated domains of politics and technoscience, nature and society. Rather than a proper, modern space that celebrates state power through technology, the museum continuously renders firm ontological boundaries fluid. Looking into the RID as a parliament of things, and especially inside the cosmopolitical materials exhibited in the museum, I have shown that Thai water engineers might be even more nonmodern than Latour would have imagined.

\section{Author Biography}

Jakkrit Sangkhamanee is an assistant professor in anthropology at the Faculty of Political Science, Chulalongkorn University, Thailand. His current research focuses on the history and politics of hydrological knowledge and infrastructure construction in Thailand. He is also interested in the sociotechnical community of water engineers in Thai bureaucratic circle.

\section{Acknowledgements}

I would like to thank Atsuro Morita and Casper Bruun Jensen for inviting me to join a research project on Environmental Infrastructures as well as providing comments on the earlier version of my work. I also thank anonymous reviewers and the editors of ESTS for valuable inputs to this paper.

\section{References}

Biggs, D. 2006. "Reclamation Nations: The US Bureau of Reclamation's Role in Water Management and Nation Building in the Mekong Valley, 1945-1975" Comparative Technology Transfer and Society 4 (3): 225-246.

Blake, D.J.H. 2015. “King Bhumibol: The Symbolic 'Father of Water Resources Management' and Hydraulic Development Discourse in Thailand" Asian Studies Review 39 (4): 649-668.

Brummelhuis, H.t. 2007. King of the Waters: Homan van der Heide and the Origin of Modern Irrigation in Siam. Chiang Mai: Silkworm Books.

Carroll, P. 2006. Science, Culture, and Modern State Formation. Berkeley, Los Angeles and London: The University of California Press.

Descola, P. 2013. Beyond Nature and Culture. Chicago: The University of Chicago Press.

Ferguson, J. and R. Patterson. 2013. Ferguson's Lectures on Select Subjects in Mechanics, Hydrostatics, Hydraulics, Pneumatics, Optics, Geography, Astronomy, and Dialing: With Notes and an Appendix Adapted to the Present State of the Arts and Sciences. Charleston: Nabu Press.

Hoag, C. 2011. "Assembling Partial Perspectives: Thoughts on the Anthropology of Bureaucracy" PoLAR: Political and Legal Anthropology Review 34 (1): 81-94.

Jensen, C.B. 2015. "Experimenting with Political Materials: Environmental Infrastructures and Ontological Transformations" Distinktion: Scandinavian Journal of Social Theory (16) 1: 17- 
30.

Jumsai, S. 1988. Naga: Cultural Origins in Siam and the West Pacific. Oxford: Oxford University Press.

Latour, B. 1987. Science in Action: How to Follow Scientists and Engineers Through Society. Cambridge: Harvard University Press.

.1993. We Have Never Been Modern. Translated by Catherine Porter. Cambridge, MA: Harvard University Press.

. 1996. "Do Scientific Objects Have a History? Pasteur and Whitehead in a Bath of Lactic Acid" Common Knowledge 5 (1): 76-91.

McCargo, D. 2005. "Network Monarchy and Legitimacy Crises in Thailand" The Pacific Review 18 (4): 499-519.

Mukerji, C. 2003. "Intelligent Uses of Engineering and the Legitimacy of State Power" Technology and Culture 44(4): 655-676

Pickering, A. 1995. The Mangle of Practice: Time, Agency, and Science. Chicago and London: University of Chicago Press.

Royal Irrigation Department (RID). 1966. In Memory of 60 Year Anniversary Merit Ceremony for M.L. Xujati Kambhu (in Thai). Bangkok: Royal Irrigation Department. . 1969. The Works of M.L. Xujati Kumbhu (in Thai). Bangkok: Royal Irrigation Department. . 1986. Eighty-Four Years Royal Irrigation Department (in Thai). Bangkok: Royal Irrigation Department. . 2007a. RID Museum for Heavy Engineering (in Thai). Nonthaburi: Royal Irrigation Department.

. 2007b. Sixty Year Hydrology of Royal Irrigation Department (in Thai). Bangkok: Royal Irrigation Department.

Sangkhamanee, J. 2010. Hydraulics of Power and Knowledge: Water Management in Northeastern Thailand and the Mekong Region. PhD Dissertation. Canberra: The Australian National University.

Sneddon, C. 2015. Concrete Revolution: Large Dams, Cold War Geopolitics, and the US Bureau of Reclamation. Chicago and London: The University of Chicago Press.

Snidvongs Na Ayudhya, C. 2007. Cremation Volume of Chulanope Snidvongs Na Ayudhya. Bangkok: Publisher unknown.

Weber, Max. 1978. "Bureaucracy" in Economy and Society. Translated by Guenther Roth and Claus Witch. Berkeley: The University of California Press. 